Br Heart F 1981; 46: 571-3

\title{
Dissection of ascending aorta
}

\section{Rare complication of aortocoronary venous bypass surgery}

\author{
P BOPP, J J PERRENOUD, M PERIAT \\ From the Centre and Division of Cardiology, Department of Medicine, University Hospital, Geneva, \\ Switzerland
}

SUMMARY Dissection of the ascending aorta is a rare complication of aortocoronary bypass surgery. A 63-year-old man who had received a double graft was found to have dissection of the ascending aorta, which was shown angiographically four months after operation. Since the patient was asymptomatic, operation was postponed. He has been followed up regularly and two years later his condition is still satisfactory.

Aortocoronary bypass surgery has gained wide acceptance in the treatment of symptomatic ischaemic heart disease. Myocardial infarction, pericardial tamponade, pericarditis, and postoperative infection are some of the more frequently encountered complications of the procedure but the occurrence of aortic dissection is rare, and so far only a few cases have been described. This paper reports such a patient who has been followed up for two years.

\section{Case report}

A 61-year-old man was referred on 20 October 1977 for coronary arteriography. He had been suffering from angina pectoris since 1970 and from exertional dyspnoea since 1976. There was no history of systemic hypertension. He was in good physical condition with a normal blood pressure (110/80 $\mathrm{mmHg}$ ) in both arms, a regular pulse, normal heart sounds without associated murmurs, and no signs of cardiac failure. The electrocardiogram disclosed an old anterior myocardial infarction. The chest $x$-ray film was normal. Cardiac catheterisation showed a normal left ventricular end-diastolic pressure (10 $\mathrm{mmHg}$ ); the cineventriculogram disclosed apical dyskinesia but otherwise well-preserved dynamics (ejection fraction: $62 \%$ increasing to $70 \%$ in a postextrasystolic beat). The diameter of the supravalvular ascending aorta was normal with no calcification of the aortic wall on screening.

At coronary arteriography there was a proximal subtotal narrowing of the left anterior descending artery immediately distal to the first septal and first diagonal branches, and a subtotal stenosis of the circumflex artery in its mid-portion. The right coronary artery showed only minor lesions.

Using saphenous vein grafts, a double left aortocoronary bypass was performed on 20 December 1977. The arterial cannula was located in the left femoral artery. The distal venous anastomoses were performed first, and the proximal ends of the grafts were implanted on the left a.terolateral aspect of the ascending aorta, under single partial tangential clamping. No cardioplegic solution was used. No damage to the aortic wall was observed by the surgeon. There were no immediate complications and recovery was uneventful. No cardiac murmurs were detected on auscultation at that time, but at follow-up later an early diastolic murmur was noted at the left sternal border. On the chest $x$-ray film the ascending aortic outline seemed more prominent than on the preoperative film. Angina had been relieved.

On 18 April 1978, an aortogram (Fig.) disclosed a false lumen in the ascending aorta, starting from the area of proximal anastomosis of the grafts and reaching up to the aortic arch. In addition, moderate aortic regurgitation was noted. Both coronary bypasses were visualised and their patency confirmed by selective injections. Coronary arteriography showed that both left anterior descending and circumflex arteries were occluded at the previously stenosed areas; there was no progression of the lesions in the right coronary artery. Left ventricular end-diastolic pressure $(12 \mathrm{mmHg})$ and ejection 
fraction $(60 \%)$ were still within normal limits.

As the patient was asymptomatic and as reoperation would entail a major risk, a decision was made to postpone surgery. The patient has since been followed up regularly and so far (January 1980 ) his condition remains satisfactory; his chest $x$-ray film is unchanged.

\section{Discussion}

To the best of our knowledge only 12 other cases of aortic dissection occurring after aortocoronary surgery have been reported so far (Table). This is the first time that this complication has been seen by us in a series of approximately 1000 similar operations. In the absence of such predisposing conditions as Marfan's syndrome or cystic medionecrosis atherosclerosis seems to be important. It was noted in all four cases of Litchford et al. ${ }^{1}$ Furthermore, a past history of hypertension can often be elicited in these patients, as in both cases of Boruchow et al. ${ }^{2}$ and in all four cases of Nicholson et $a .^{3}$ and was thus present in six out of nine subjects $(66 \%)$ in whom this aetiological factor was mentioned. Hypertension was present in 81 per cent of the 62 necropsy cases of spontaneous dissection reported by Lindsay and Hurst. ${ }^{4}$ By increasing intraluminal tension, a raised blood pressure may exert dire effects especially in a dilated and tortuous aorta (Laplace's law). Thus, both atherosclerosis and hypertension are known to predispose to the development of aortic dissection, ${ }^{5}$ and the importance of pre-existing disease of the aortic wall must not be overlooked, but it is surgical trauma that acts as the trigger mechanism, whether through cannulation $^{6}$ or clamping. Both techniques of crossclamping $^{1}$ and of partial clamping ${ }^{2}$ have been indicted. Once the intimal teat has occurred other factors such as pulse wave characteristics (max.

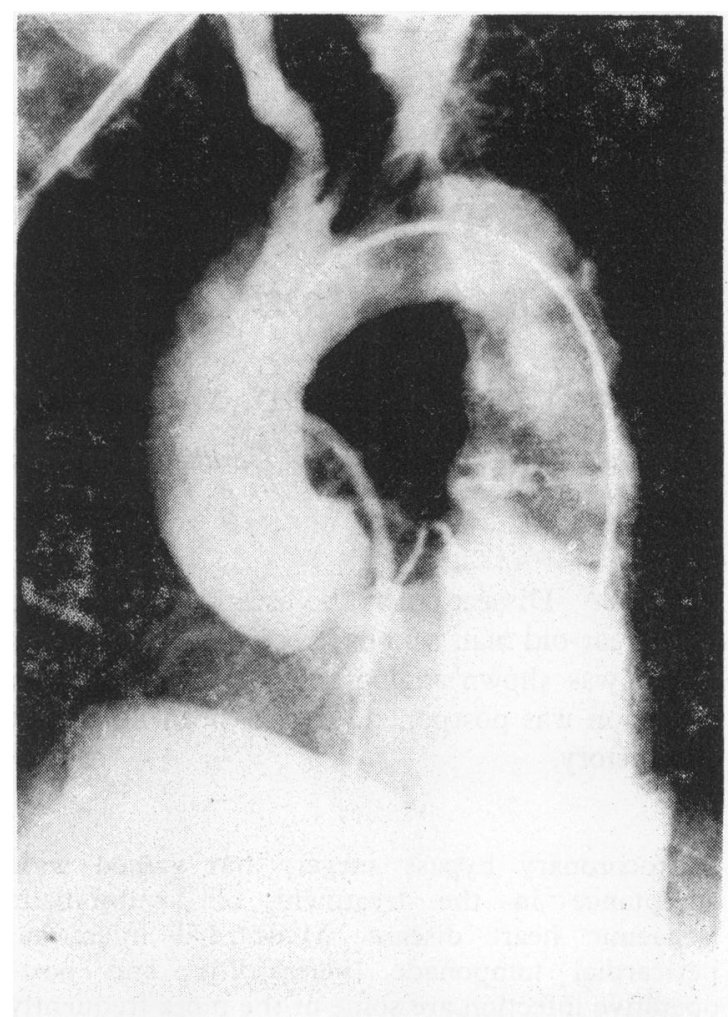

Fig. Aortogram.

$\mathrm{dP} / \mathrm{dt}^{7}$ ) also influence the extent of the lesion.

Kimbiris et al. ${ }^{8}$ have pointed out that the preoperative fluoroscopic visualisation of calcification of the aortic wall can help the surgeon to choose more carefully the sites of venous anastomosis. In such cases, implantation of the grafts may entail a greater risk. Aortic dissection can also develop

Table Aortic dissection complicating coronary venous bypass surgery

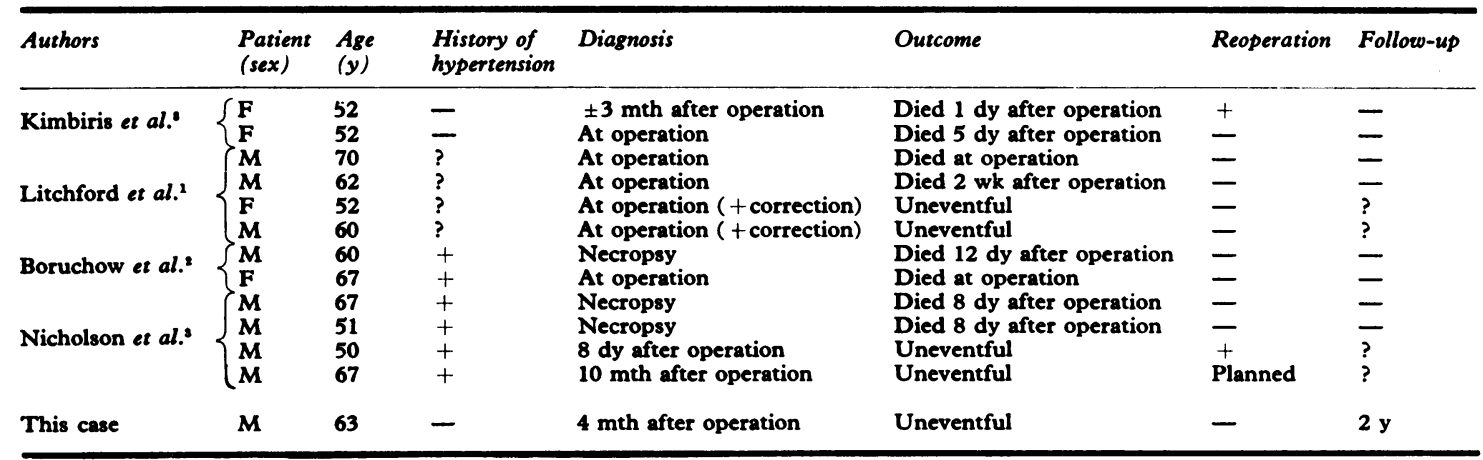


in isolated valvular replacement, ${ }^{6}$ though aneurysmal dilatation without dissection may equally be

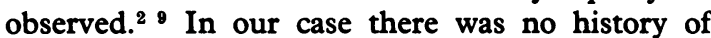
hypertension; the severity of aortic atherosclerosis, however, was unknown. Though no intraoperative complications occurred, the relation between coronary bypass and aortic dissection seems probable, even if the diagnosis was made only four months after operation. The complication is an ominous one with a poor prognosis and eight of the 13 patients $(62 \%)$ reported (Table) died, either at operation (two cases), in the postoperative period (five cases), or during reoperation (one case).

In their series of postmortem studies, Lindsay and Hurst $^{4}$ report a somewhat similar survival period of three weeks as the longest observed between the onset of symptoms and death in spontaneous dissection. The two year asymptomatic survival in our patient thus seems exceptional, and reoperation may eventually have to be performed.

The importance of an early diagnosis cannot be overemphasised, and our case illustrates the need for careful postoperative medical scrutiny with particular reference to new heart murmurs and changes in chest films.

The authors are indebted to Dr J Chatillon for referring the patient and to Dr N Radovanovic for the surgical data.

\section{References}

1 Litchford B, Okies JE, Sugimura S, Starr A. Acute aortic dissection from cross-clamp injury. $f$ Thorac Cardiovasc Surg 1976; 72: 709-13.

2 Boruchow IB, Iyengar R, Jude JR. Injury to ascending aorta by partial-occlusion clamp during aortocoronary bypass. $\mathcal{F}$ Thorac Cardiovasc Surg 1977; 73: 303-5.

3 Nicholson WJ, Crawley IS, Logue RB, Dorney ER, Cobbs BW, Hatcher CR Jr. Aortic root dissection complicating coronary bypass surgery. $\mathrm{Am} \mathcal{F}$ Cardiol 1978; 41 : 103-7.

4 Lindsay $\mathrm{J} \mathrm{Jr}$, Hurst JW. Clinical features and prognosis in dissecting aneurysm of the aorta. Circulation 1967; 35: 880-8.

5 Braunstein $\mathrm{H}$. Pathogenesis of dissecting aneurysm. Circulation 1963; 28: 1071-80.

6 Salama FD, Blesovsky A. Complications of cannulation of the ascending aorta for open heart surgery. Thorax 1970; 25: 604-7.

7 Prokop EK, Palmer RF, Wheat MW Jr. Hydrodynamic forces in dissecting aneurysms. Circ Res 1970; 27: 121-7.

8 Kimbiris D, Dreifus LS, Adam A, Blanco G, Linhart $\mathrm{JW}$. Dissection and rupture of the ascending aorta. Chest 1975; 68: 313-6.

9 Flick WF, Hallermann FJ, Feldt RH, Danielson GK. Aneurysm of aortic cannulation site. $\mathcal{f}$ Thorac Cardiovasc Surg 1971; 61: 419-23.

Requests for reprints to Dr P Bopp, Centre of Cardiology, University Hospital, CH-1211 Geneva 4, Switzerland. 